\title{
PROJECT RISK SIMULATION UNDER UNCERTAIN CONSTRUCTION DURATION
}

\author{
Kun-Jung Hsu \\ Department of Construction Technology \\ Leader University \\ No.188 Sec. 5, An-Chung Rd. \\ Tainan, 709, TAIWAN
}

\begin{abstract}
This paper establishes a two-phase model to explore the financial risk of construction project under uncertain construction duration. Treated as a random variable in the model, the construction duration affects the random present worth of cash flow in both construction and operation phases. An illustration of BOT project under uncertain construction duration was utilized for simulation. The simulation result was applied to reveal how uncertain construction duration affects project risk. The paper also shows how the standard deviation of the NPV increases whenever the variance of construction duration rises, thus accentuating the contingency of the project. The results' analysis extended to the discussion of its effect on the probability of negative NPV and its theoretical meanings.
\end{abstract}

\section{INTRODUCTION}

Capital investment often involves substantial construction. Therefore, the fund needed in the initial stage is huge. Usually, after the construction initiated, in case of serious delay or work suspension, the starting time for initial business operation is doomed to procrastinate. It implies detrimental influences, particularly for a chartered contract with fixed term. Usually, a construction project is assumed to be completed on schedule within predetermined budget, and operates toward the end of the project term under the designed capacity. So, it is commonly seen in the business of capital investment to include construction project management team credited with sizable resources. In such case, construction work items are documented in detail and charted with accuracy. These management activities are executed to make sure the works get completed on schedule.

Most of the net present value (NPV) calculations in the project evaluation literatures assumed fixed construction durations. The risks generated from this variation that could affect the project evaluation is still lack discourse in theory. As for risk analysis, it is formulated by assessing the probability distribution of the factors affecting financial economic criterion for the alternative selected (Hillier 1963, Hertz 1964, Hespos and Strassmann 1965, Wagle 1967, Hillier 1971, Greenberg 1982). The risk generated from the variation of construction duration could affect both the present worth cash flow in construction phase and operation phase. This correlated effect is often mentioned in the realm of professional practice, but not thoroughly explored and clarified.

This paper first presents a two-phase cash flow model depicting the NPV resulted from project finance activities. The construction duration is treated as a random variable in the formulation of the model, which is used to derive the risk magnitude affecting NPV, and the probability of resulting in negative NPV. An illustrative example of BOT project under uncertain construction duration was then utilized for simulation. The conclusion remark is drawn in the final section.

\section{THE MODEL}

NPV is the most popular index in project evaluation. In most BOT projects, the general contractor faces a fixed period of implementation in accordance with the relevant contract. In such cases, the period of the project is limited by $N$-year concessions. If $A_{j}$ is the net cash flow arising in year $j$ connected with a capital investment project. The NPV of a project is

$$
N P V=\sum_{j=0}^{N} \frac{A_{j}}{(1+i)^{j}},
$$

where $i$ is discrete discount rate. The NPV of such project can be presented as continuous cash flow of period from 0 to $N$, and can be rewritten as definite integral form in equation (2)

$$
N P V=\int_{0}^{N} A_{j} e^{-r j} d j,
$$


where $r$ is the nominal continuous-compound interest rate, and $e$ is the base of natural logarithms. For practical purposes, we can use $r=\ln (1+i)$ in order to relate $i$ to $r$. Let $n_{1}$ represents the end of the construction phase at which the positive net cash-inflow of the operation phase begins.

Generally speaking, project investment is always planned to generate income that covers the operating cost and the debt services resulted from project related financing activities. In the beginning of a construction project, it requires a sizable fund to cover the acquisition of land, machinery, materials, engineering and construction work. Meanwhile, in most cases, there is no income generated from the projects. The cost of a project starts to accumulate as soon as the capital is invested. The magnitude of risk grows in proportion to the accumulated cost throughout the entire construction duration. In case of work suspension during construction at any time, the deferred cash income for the project becomes unavoidable. So let $j=0-n_{1}$ represent period of the construction phase, and $j=n_{1}-N$ represent period of the operation phase. The NPV of such a BOT project thus can be represented as a cash flow model with a twophase framework, and rewritten equation (2) as

$$
N P V=\int_{0}^{n_{l}} A_{j} e^{-r j} d j+\int_{n_{l}}^{N} A_{j} e^{-r j} d j
$$

The first term represents the total present value of the cash flow during the construction phase, and the second term represents the total present value of the cash flow during the operation phase. In equation (3), $A_{j}$ represents the net cash flow that occurs in year j. $A_{j}$ can be treated as the summation of cash inflows (including operation income, rental income etc.) and cash outflows (including operation expenditures, maintenance fees etc).

In the context of project evaluation, operation expenditures and maintenance fees are usually treated as a component of the operation income or the rental income, respectively. A project evaluation may also assign a constant growth rate for a revenue or expenditure item. Also, the net cash flow of operation expenditures and maintenance fees from period $\mathrm{n}_{1}$ to $\mathrm{N}$ in the operation phase can be calculated as the annual value in the evaluation. In order to control for other variables constant and explore the effect of the uncertain construction period on project risk both in analytics and simulation model, we need some reasonable simplification. For example, the risk during the operation phase is assumed to be negligible. This simplification results in a more parsimonious model without any serious loss of realism.

If the total construction cost $C_{l}$ is paid at the end of construction phase, the $\mathrm{PV}$ of the single payment at $n_{l}$ is $C_{1} e^{-r j}$. Let $a_{2}$ represents a uniform cash flow in the time horizon of the operation phase. The NPV can be represented as

$$
N P V=C_{1} e^{-r n_{1}}+\int_{n_{1}}^{N} a_{2} e^{-r j} d j
$$

Equation (4) can be simplified as

$$
N P V=C_{1} e^{-r n_{1}}+\frac{a_{2}}{r}\left(e^{-r n_{1}}-e^{-r N}\right)
$$

The first term in equation (5) represents the present value of the total construction cost paid at the end of the construction phase $\left(P V_{l}\right)$. The second term represents the present value of the continuous uniform cash flow of the operation phase $\left(\mathrm{PV}_{2}\right)$. Mathematically, it can be interpreted as the present value of the same perpetual annuity, $a_{2}$ (from time $\mathrm{N}$ onward) being subtracted from the present value of an infinite sequence of the annual cash flow $a_{2}$ (from time $n_{1}$ onward).

\section{THE MARGINAL EFFECT OF NPV UNDER UNCERTAIN CONSTRUCTION DURATION}

In equation (5), whenever construction duration postpone, constant $N$-year concessions will induce a loss of cash inflow in operation phase. But construction duration postpone will also lower the present worth of the total construction cost because of delay payment and save the time cost of early payment. So whenever construction duration postpone, if loss of cash-inflow in operation phase can be compensated by interest saving of total construction cost payment in construction phase, then postpone of construction duration will increase the project NPV value. But if the saving of total construction cost in construction phase cannot compensate the losses of cash-inflow in operation phase, then postpone of construction duration will decrease the project NPV value.

But whenever $n_{1}$ is a random variable and with a given probability distribution. The expectation and variance of present value of the cash outflow of $C_{l}$ which depends on the construction duration $n_{l}$ will be more complicate. Let expected present value of $C_{l}$ denoted as $E\left[P V_{l}\left(n_{1}\right)\right]$, and is given by

$$
E\left[P V_{l}\left(n_{1}\right)\right]=E\left[C_{1} e^{-r n_{1}}\right]=E\left[C_{1}\right] \bullet E\left[e^{-r n_{1}}\right] .
$$

Since the present value factor is not a linear function of $n_{1} ; E\left[e^{-r n_{1}}\right] \neq \mathrm{e}^{-r E\left[n_{l}\right]}$, we cannot calculate $E\left[P V_{l}\left(n_{l}\right)\right]$ by inserting $E\left(n_{1}\right)$ in $n_{1}$ in (8). The expec- 
tation of $e^{-r n_{l}}$ can be written as the Laplace Transform of the probability density function

$$
E\left(e^{-r n_{1}}\right)=L_{n_{l}}(r)
$$

The variance of $e^{-r n_{l}}$ can be written as

$$
\operatorname{Var}\left(e^{-r n_{1}}\right)=L_{n_{I}}(2 r)-\left[L_{n_{I}}(r)\right]^{2} \quad .
$$

Equation (8) can be rewritten as

$$
E\left[P V_{l}\left(n_{l}\right)\right]=\mu_{c_{l}} L_{n_{l}}(r) .
$$

The variance of the present value of such a single payment is

$$
\begin{aligned}
& \operatorname{Var}\left[P V_{l}\left(n_{l}\right)\right]=\left(\mu_{c_{l}}^{2}+\sigma_{c_{l}}^{2}\right) \operatorname{Var}\left(e^{-r n_{l}}\right)+\sigma_{c_{l}}^{2}\left[E\left(e^{-r n_{l}}\right)\right]^{2} \\
& \quad=\left(\mu_{c_{l}}^{2}+\sigma_{c_{l}}^{2}\right)\left[L_{n_{l}}(2 r)-\left(L_{n_{1}}(r)\right)^{2}\right]+\sigma_{c_{l}}^{2}\left[L_{n_{l}}(r)\right]^{2} .
\end{aligned}
$$

The Laplace Transform of different probability density functions has been explored by Young and Contreras (1975) and Rosenthal (1978). Given a probability distribution function of $n_{1}, E\left(e^{-r n_{1}}\right)$ and $\operatorname{Var}\left(e^{-r n_{1}}\right)$ can be derived using the Laplace Transform.

Let $\mu_{n_{l}}$ represents mean value of construction duration, one can simulates $\operatorname{Var}\left(e^{-r n_{1}}\right)$ vs. $\mu_{n_{l}}$ and $\operatorname{Var}\left(e^{-r n_{1}}\right)$ vs. $r$. The results of simulation $\operatorname{Var}\left(e^{-r n_{1}}\right)$ vs. $\mu_{n_{l}}$ represent in Figure 1, which show a decreasing curve. But the non-linear relationship between $\operatorname{Var}\left(e^{-r n_{1}}\right)$ vs. $r$ will be more complicated. The paper simulates $\operatorname{Var}\left(e^{-r n_{1}}\right)$ vs. $r$ and shows results the nonlinear relationship in Figure 2. The non-linear relationship shows the direction of marginal effect on $\operatorname{Var}\left(e^{-r n_{1}}\right)$ vs. $r$ will be non-definite.

The variance of the NPV of the total project will be affected by marginal change or the variance of $n_{1}$. But, the component of the effect will be more complicatedly. In such situation, the paper give an illustrative example to simulate the two-phase model in Section 4, then discusses the simulation results in details thereafter.

\section{SIMULATION ON ILLUSTRATIVE EXAMPLE}

In most BOT projects, the general contractor faces a fixed period of implementation in accordance with the relevant

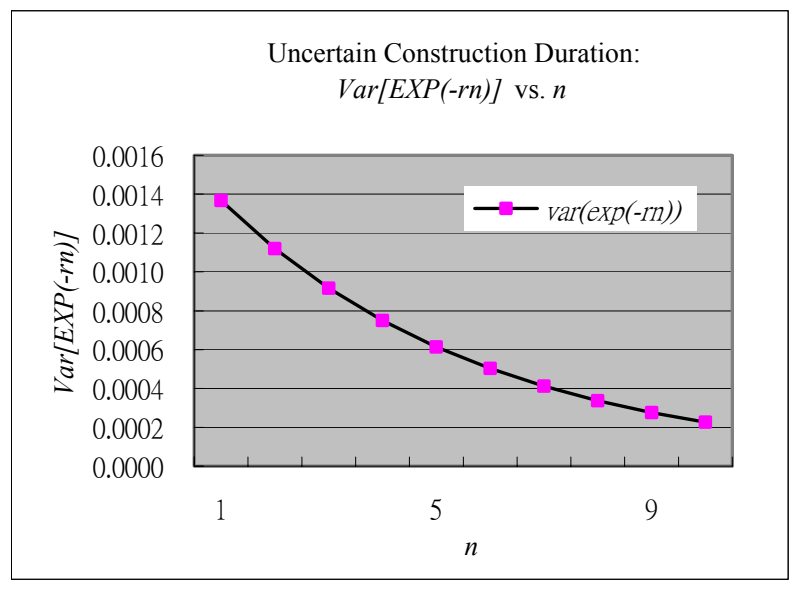

Figure 1: Uncertain Construction Duration: $\operatorname{Var}\left(e^{-r n_{1}}\right)$ vs. $\mu_{n_{1}}$

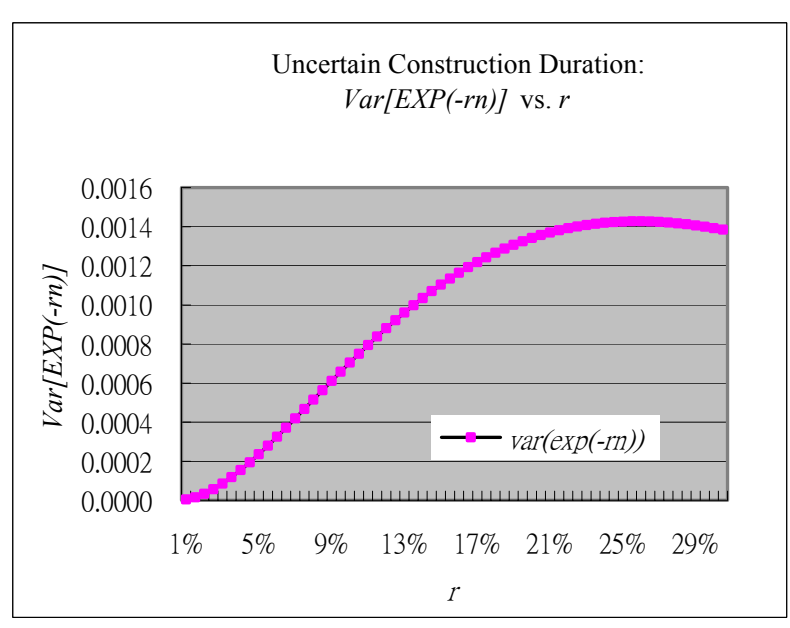

Figure 2: Uncertain Construction Duration:

$$
\operatorname{Var}\left(e^{-r n_{1}}\right) \text { vs. } r
$$

contract. The period of the project is limited by $N$-year concessions. The financial index of a BOT-Project can be represented as a NPV cash flow model with a two-phase form, which has been discussed in Section 3. In order to reveal how construction duration uncertainty affects project risk, the simulation case in this paper was largely simplified from the case study of Taiwan High Speed Rail (THSR). So that result and meaning exhibited here is applicable in similar case.

Bureau of Taiwan High Speed Rail (BOTHSR) implemented BOT policy and invited private sectors to finance and construct the HSR Project in 1996. THSRC and the ROC Ministry of Transportation and Communications signed the BOT Agreement. Government concessions awarded to THSRC the construction and operation of the $345 \mathrm{~km}$ HSR Project, the management of subsidiary commercial enterprises, and the development of the five stations 
areas (include 35 year concessions of Construction and Operation, the Station Zone Development Agreement, 50 years concessions of Business Development Land Agreement, the Memorandum on Government Commitments, and the Contract Execution Memorandum). By the year 2000, THSRC entered into all major civil works contracts. The construction commenced soon after, and scheduled to operate at the end of 2005. Total construction budget for HSR project approximates 441.9 billion NTD (http://www. thsrc. com. tw/emain/hsr/hsr.asp).

In HSR Project, the operation expenditure is represented as the function of ridership and the growth rate of ridership. Let $C_{2}$ be the operation expenditure of the first year operation phase, $g_{I}$ is the growth rate of ridership, the present value of total operation expenditure $\left(P V_{21}\right)$ can be written as

$$
P V_{21}=C_{2}\left[\frac{1+\left(1+g_{1}\right)^{n_{2}}-(1+r)^{-n_{2}}}{r-g_{1}}\right] *(1+r)^{-n_{1}}
$$

Let $R_{1}$ represents operation income of the first year operation phase, $g_{2}$ is the growth rate of average ridership price, the present value of total operation income $\left(P V_{22}\right)$ can be written as

$$
P V_{22}=R_{l}\left[\frac{1-\left(1+g^{*}\right)^{N}(1+r)^{-N}}{r-g^{*}}\right] *(1+r)^{-n_{l}},
$$

where $g^{*}=g_{1}+g_{2}+g_{1} \times g_{2}$. For simplification, let average income of the total the station zone development and business development land be constant $\left(R_{2}\right)$. The present value of total development $\left(P V_{23}\right)$ can be written as

$$
P V_{23}=R_{2}\left[\frac{(1+i)^{n_{2}}-1}{i(1+i)^{n_{2}}}\right] *(1+i)^{-n_{1}}
$$

So one can decompose the $N P V$ and rewrite equation (5) as

$$
N P V=V P_{11}+P V_{21}+P V_{22}+P V_{23} .
$$

The risk profile of THSR Project under uncertain construction duration is shown in Table 1, Figure 3, Figure 4. In which Monte Carlo Simulation was applied using software@RISK and run 10000 iterations. The simulation also shows the component of project risk under uncertain duration. In Table 2, the component shares of the project risk show that the main cost risk derive from the effect on construction cost. The main revenue risk derive from the effect on totaling the station zone development and business development land.

Table 1: Risk Profile of the Project under Uncertain Construction Duration (Unit: 100 Million NTD)

\begin{tabular}{|r|r|}
\hline CL(\%) & Value \\
\hline $5 \%$ & -224.71 \\
\hline $10 \%$ & -167.82 \\
\hline $15 \%$ & -128.16 \\
\hline $20 \%$ & -96.00 \\
\hline $25 \%$ & -67.90 \\
\hline $30 \%$ & -42.30 \\
\hline $35 \%$ & -18.18 \\
\hline $40 \%$ & 4.98 \\
\hline $45 \%$ & 27.72 \\
\hline $50 \%$ & 50.35 \\
\hline $55 \%$ & 73.25 \\
\hline $60 \%$ & 96.85 \\
\hline $65 \%$ & 121.54 \\
\hline $70 \%$ & 147.88 \\
\hline $75 \%$ & 176.73 \\
\hline $80 \%$ & 209.38 \\
\hline $85 \%$ & 248.10 \\
\hline $90 \%$ & 297.91 \\
\hline $95 \%$ & 373.91 \\
\hline Minimum & -531.58 \\
\hline Maximum & 979.62 \\
\hline Mean & 59.34 \\
\hline Std Dev & 182.44 \\
\hline Variance & $33,283.86$ \\
\hline & \\
\hline
\end{tabular}

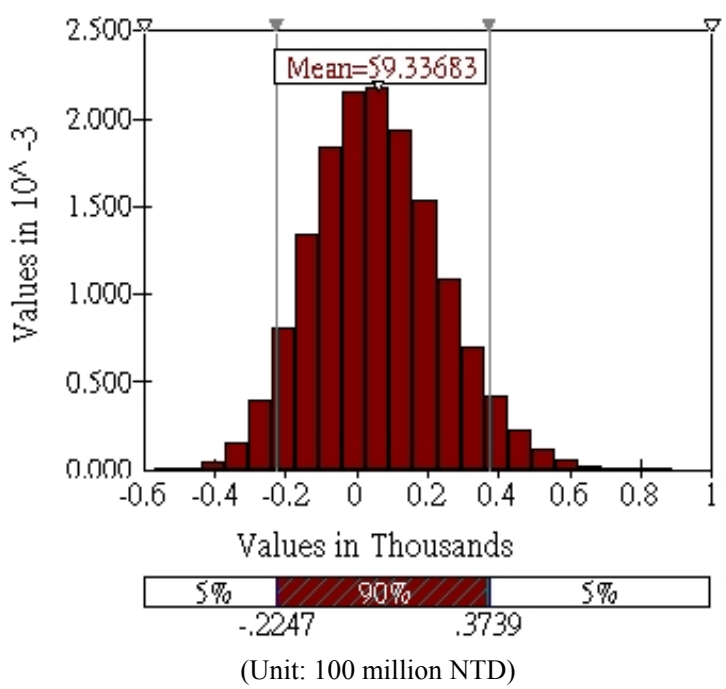

Figure 3: PDF of the Project Risk under Uncertain Construction Duration 


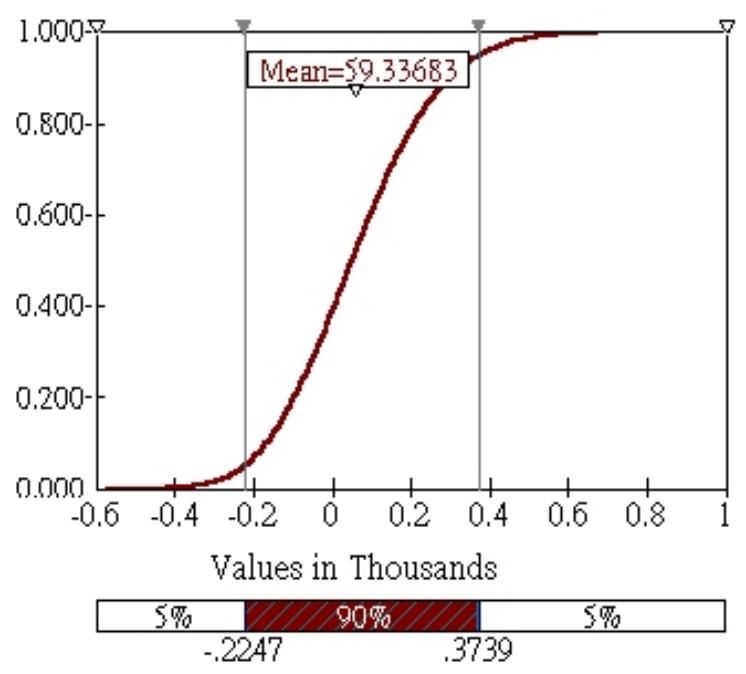

(Unit: 100 million NTD)

Figure 4: CDF of the Project Risk under Uncertain Construction Duration

Following the same process, it's easy to simulate how the variance of construction duration will increase the variance project NPV. So the standard deviation of the project NPV increases as well. Thus affect the probability areas of a negative NPV of the project. Given the expectation and the variance of project NPV, the probability of a negative NPV of the project investment can be derived as

$$
\begin{aligned}
\operatorname{Pr}(N P V \leq 0) & =\operatorname{Pr}\left(\frac{N P V-\mu_{N P V}}{\sqrt{\sigma_{N P V}^{2}}} \leq \frac{0-\mu_{N P V}}{\sqrt{\sigma_{N P V}^{2}}}\right) \\
& =\operatorname{Pr}\left(Z \leq \frac{-\mu_{N P V}}{\sqrt{\sigma_{N P V}^{2}}}\right),
\end{aligned}
$$

where

$$
Z=\frac{N P V-\mu_{N P V}}{\sqrt{\sigma_{N P V}^{2}}} .
$$

In equation (17), the term on the right hand side of the bracket includes a negative sign, so that whenever the standard deviation of NPV $\left(\sigma_{N P V}\right)$ increases, the critical value of Z-Score $\left(\frac{-\mu_{N P V}}{\sqrt{\sigma_{N P V}^{2}}}\right)$ for a NPV $\leq 0$ will also increase. Hence, the critical value of Z-Score increases and moves toward the right hand side along the axis of the probability distribution function, then increasing the area under the probability distribution function from $-\infty \rightarrow \mathrm{Z}$, which will increase the probability of a negative project NPV. This will increase contingency of the BOT-Project.

\section{CONCLUSION REMARK}

Capital investment often involves substantial construction. Construction project management is executed to control and insure the work to be completed on schedule. Most of the net present value calculations in the project evaluation literatures assumed fixed construction durations. But this paper allows the construction duration to be random, which will be more realistically applicable for project management in large capital investment projects. This relaxation provides profound meanings. An illustrative example of BOT-Project under uncertain construction duration was then simulated. In the end, the paper shows that whenever the variance of the construction duration increases, the standard deviation of the project NPV increases as well. Hence, increase the probability of a negative project NPV.

\section{ACKNOWLEDGMENTS}

The author would like to thank Professor David Emanuel Anderson for his English grammar review of the paper.

\section{REFERENCES}

Bureau of Taiwan High Speed Rail. 2004. Project Overview of the high speed railroad system in Taiwan. Available online via <www.thsrc.com.tw/emain/hsr/ hsr. asp> [accessed January 15, 2004].

Greenberg, Joel S. 1982. Investment Decisions: The Influence of Risk and other factors, New York: Research and Information Service, American Management Associations.

Hertz, D.B. 1964. Risk Analysis in Capital Investment, Harvard Business Review 42: 95-106.

Hespos, R. G. and P. A. Strassmann. 1965. Stochastic Decision Trees for the Analysis of Investment Decisions, Management Science 11: 244-259.

Hillier, Frederick S. 1963. The Derivation of Probabilistic Information for the Evaluation of Risk Investment, Management science 9: 443-459.

Hillier, Frederick S. 1971. The evaluation of risky interrelated investments, Amsterdam: North-Holland.

Rosenthal, Richard E. 1978. The Variance of Present Worth of Cash Flows Under Uncertain Timing, The Engineering Economist 23: 163-170.

Wagle, B. 1967. A Statistical analysis of risk in investment projects, Operational research quarterly 18: 13-33.

Young, D. and L. E. Contreras. 1975. Expected Present Worths of Cash Flows Under Uncertain Timing, The Engineering Economist 20: 257-268. 
Table 2: Components of the Project Risk Simulation under Uncertain Construction Duration (Unit: 100 million NTD)

\begin{tabular}{|c|c|c|c|c|c|c|}
\hline \multirow[b]{2}{*}{ Name } & \multicolumn{2}{|c|}{ Cost } & \multicolumn{2}{|c|}{ Revenue } & \multirow[b]{2}{*}{ NPV } & \multirow[b]{2}{*}{$\begin{array}{l}\text { Construction } \\
\text { Duration }\end{array}$} \\
\hline & $\begin{array}{c}\text { Construction } \\
\text { Cost } \\
\text { PV }_{11}\end{array}$ & $\begin{array}{c}\text { Operation } \\
\text { Expenditure } \\
\mathrm{PV}_{21}\end{array}$ & $\begin{array}{l}\text { Operation } \\
\text { Income } \\
\mathrm{PV}_{22}\end{array}$ & $\begin{array}{l}\text { Revenue from } \\
\text { the station zone } \\
\text { development } \\
\text { and business } \\
\text { development } \\
\text { land } \mathrm{PV}_{23}\end{array}$ & & \\
\hline Mean & $-3,794.17$ & -0.12 & 36.70 & $3,816.94$ & 59.34 & 5 \\
\hline & & $-3,794.29$ & & $3,853.64$ & & \\
\hline Source & $100 \%$ & $0 \%$ & $1 \%$ & $99 \%$ & & \\
\hline Std Deviation & -136.11 & -0.01 & 3.03 & 315.52 & 182.44 & 0.8165 \\
\hline Source & $-75 \%$ & $-0 \%$ & $2 \%$ & $173 \%$ & & \\
\hline & & -136.12 & & 318.56 & & \\
\hline & $100 \%$ & $0 \%$ & $1 \%$ & $99 \%$ & & \\
\hline $\begin{array}{l}\text { Source of } \\
\text { Variance }\end{array}$ & $18,525.58$ & 0.00 & 9.20 & $99,555.10$ & & \\
\hline & 1.37 & & 957.26 & & & \\
\hline Variance & $-2 * 412.94$ & $-2 * 42,945.49$ & $-2 * 0.03$ & $-2 * 3.18$ & $\begin{array}{c}\text { Total } \\
\text { Variance }= \\
33,283.86\end{array}$ & 0.6667 \\
\hline
\end{tabular}

\section{AUTHOR BIOGRAPHY}

KUN-JUNG HSU is Assistant Professor and Director of the Department of Construction Technology, Leader University. He received his Ph.D. degree in Civil Engineering from National Taiwan University. He is also a senior lecturer of the Graduate Institute of Building and Planning, Taiwan University. Dr. Hsu had twenty years' experience in professional practice as a senior architect and construction manager. He teaches in Statistics, Regression Analysis, Economics, Construction Economics, Quantitative Method, and Construction System for Architectural Design, Architectural Design, etc. His current research interests include housing economics, construction economics and special topics on project evaluation. His e-mail address is $<$ hsulmail. leader. edu. tw $>$. 